\title{
Encuentros diplomáticos entre los caciques de la frontera sur y el Cabildo de Buenos Aires, 1806 (Virreinato del Río de la Plata)
}

Diplomatic Encounters between the Caciques of the Southern Frontier and the Cabildo of Buenos Aires, 1806 (Viceroyalty of the Rio de La Plata)

DOI: http://doi.org/10.22380/20274688.556

Recibido: 23 de noviembre del 2018

Aprobado: 22 de marzo del 2019
LUISINA INÉS TOURRES* Consejo Nacional de Investigaciones Científicas

y Técnicas (CONICET), Argentina luisinatourres@gmail.com

LIDIA ROSA NACUZZI** Consejo Nacional de Investigaciones Científicas y Técnicas (CONICET), Argentina lidianacuzzi@yahoo.com.ar

\section{R E S U M $\quad \mathbf{E} \mathbf{N}$}

Proponemos examinar el caso del ofreci- la Pampa al Cabildo de Buenos Aires dumiento de ayuda militar de los caciques de rante la ocupación de la ciudad por tropas

* Licenciada en Ciencias Antropológicas, orientación sociocultural, uBA. Becaria de posgrado del CONICET, con la cual hace sus estudios de Doctorado en Antropología en la misma universidad. http://orcid.org/0000-000I-8754-1835.

** Doctora en Antropología de la UBA. Es investigadora principal del CONICET. http://orcid.org/0000$0002-2348-8606$. 
británicas en 1806. Analizamos el episodio desde la perspectiva de la historia de las relaciones interétnicas que se daban en la frontera sur desde la fundación de la ciudad en el siglo XVI, para contextualizar y discutir el relato establecido acerca de esa propuesta. Detallamos las diferentes visitas de caciques a la sala capitular y proponemos un análisis del discurso pronunciado por los líderes indígenas en una de esas visitas. Transversalmente, también reflexionamos sobre diversas cuestiones de la crítica de fuentes y su accesibilidad.

Palabras clave: construcción histórica, pueblos indígenas, diplomacia, discursos.

\section{$\begin{array}{llllllll}\mathbf{A} & \mathbf{B} & \mathbf{S} & \mathbf{T} & \mathbf{R} & \mathbf{A} & \mathbf{C} & \mathbf{T}\end{array}$}

We seek to analyze the case of the offering of military aid made by caciques of the Pampa to the Cabildo of Buenos Aires during the occupation of the city by British troops in 1806. We located this episode within the history of interethnic relations that had been taking place in the southern frontier since the foundation of the city in the $16^{\text {th }}$ century, in order to contextualize and discuss the established narrative about this offer. We elaborate on the caciques' visits to the Cabildo and propose an analysis of the speech given by some indigenous chieftains in one of those visits. Finally, we also reflect upon different issues related to source criticism and the access to them.

Keywords: historical construction, indigenous people, diplomacy, speeches.

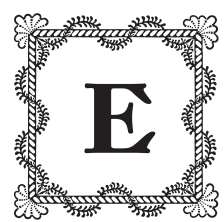

n la historia de la República Argentina existe un hecho fundante que fue la constitución de una junta de gobierno en la ciudad de Buenos Aires, luego de la destitución del virrey español en I8IO'. Como un importante antecedente de esa acción política, diversos autores les otorgan un peso especial a las acciones militares que vecinos y milicianos convocados de apuro llevaron a cabo para expulsar de la ciudad — capital del virreinato- a las tropas inglesas que la tomaron en I806 y, luego, en I807, para evitar una segunda invasión. En torno a esos hechos épicos, que retomamos en el apartado que sigue, el relato histórico también destaca que diversos caciques de la Pampa ofrecieron ayuda al Cabildo de la ciudad ante la amenaza que representaba la invasión inglesa.

I Ambas autoras hacen parte del proyecto "Grupos étnicos y espacios de frontera: estrategias políticas y relaciones interétnicas durante los siglos XVIII y XIX (Chaco, Pampa-Patagonia y la Banda Oriental)", financiado por la Universidad de Buenos Aires (UBACyT 2002013010066rba), en el marco del cual se produjo este artículo. 
En este artículo nos proponemos brindar una lectura de ese ofrecimiento, desde la perspectiva de la historia de las relaciones interétnicas que en 1806 se daban en la frontera sur de Buenos Aires, donde los grupos indígenas que durante el periodo colonial habitaron la región pampeana mantenían interacciones con diversos agentes y funcionarios desde hacía más de dos siglos (Levaggi; Nacuzzi, "Los caciques"). Buscamos contextualizar y discutir el relato establecido acerca del ofrecimiento de ayuda de los caciques, que ha sido reiterado por diversos autores y forma parte de una narración ampliamente difundida. Según los Acuerdos del Cabildo de Buenos Aires, los caciques se presentaron espontáneamente en la sala capitular, donde pronunciaron discursos que son el centro de los análisis y las argumentaciones de los autores que se han referido a estos hechos. Una revisión somera permite comprobar que muchos trabajos reproducen dichos registros de modo prácticamente literal, sin referencias a otras fuentes. Esto nos motivó para explorar otros repositorios documentales disponibles del periodo, con el fin de replantear este episodio histórico desde una perspectiva que no se encuentre mediada por las interpretaciones de otros autores y otros contextos. Creemos que la incorporación de nuevas fuentes puede aportar más precisión al análisis que ofrecemos del discurso pronunciado por los caciques, donde atenderemos a los sentidos transmitidos en el lenguaje registrado en los acuerdos.

Los Acuerdos del Cabildo de Buenos Aires son las actas de las reuniones de ese cuerpo municipal que abarcan desde su creación en el siglo Xvi hasta las primeras décadas del siglo xix. Hay cuatro actas referidas a la cuestión que nos ocupa, correspondientes a la segunda mitad de I806, en las que se registra la presencia de caciques en la sala capitular y se menciona de forma explícita el ofrecimiento de ayuda militar. Se trata de los acuerdos del 17 de agosto — cinco días luego de la "Reconquista", tal como se denominó a la finalización de la primera invasión-, el Is de septiembre y el 22 y el 29 de diciembre de I806. Asumimos que podía existir otra documentación referida a un evento tan particular como la presencia de caciques indígenas en la sala capitular, por lo que revisamos la documentación que da cuenta del paso de caciques y grupos indígenas por las guardias de la frontera sur (Serie Comandancia General de Fronteras) y el Archivo del Cabildo de Buenos Aires (ambos en el AGN). En este último ubicamos una nota fechada el 8 de julio de i806, firmada por Francisco de Lezica y Anselmo Sáenz Valiente (AGN, $A C$, IX 19-5-5) 2 , referida al envío del

2 Los firmantes eran alcaldes de primer y segundo voto del Cabildo de Buenos Aires, respectivamente (Acuerdos). 
estanciero Manuel Martín de la Calleja ${ }^{3}$ como representante del Cabildo para tomar conocimiento del estado de las guardias de la frontera y confirmar si en ellas se mantenía la buena armonía con los indios pampas. También hallamos un informe sin fecha ni firma, aunque relata en primera persona un viaje hacia territorio indígena, y que comienza: "El 8 de julio fui comisionado por el Ilustre Cabildo [...]” (AGN, $A C$, IX 19-5-5). Así, la atribución de este informe a Calleja parece directa, además de que ambos escritos se encuentran guardados uno (la nota) a continuación del otro (el informe) en un mismo legajo. Las fechas que señala el informe se refieren al mismo lapso que los acuerdos citados y se relatan los mismos hechos que en los dos primeros de ellos (del I7 de agosto y el Is de septiembre). Por ello, esta documentación resulta sumamente relevante para confrontar la información conocida y comprender con más precisión este episodio del ofrecimiento de ayuda militar al Cabildo porteńo en I806 por parte de diversos caciques de la Pampa.

\section{El relato establecido: los caciques proponen auxilio militar al Cabildo porteño}

Los episodios conocidos en la historiografía argentina como "invasiones inglesas" a Buenos Aires, en 1806 y I807, formaron parte de una única empresa militar (Gallo). Se dieron en el marco del interés británico por las colonias americanas que había surgido durante el siglo XVIII, mientras el orden colonial español entraba en crisis. La atlantización de la economía había derivado en una competencia entre las potencias europeas por la hegemonía sobre dicho océano. En ese contexto, Buenos Aires era un puerto floreciente que atraía diversas miradas. Los británicos, interesados en el Reglamento de Libre Comercio de 1778 - que amplió los intercambios entre diversos puertos españoles y americanos que venían habilitándose desde 1765 - , fueron además influidos por la presencia en Londres, desde 1785, de Francisco de Miranda, un patriota venezolano que buscaba el apoyo británico para el proyecto de la independencia americana (Cuadra y Mazzoni). Entre I804 y 1809, Gran Bretańa estuvo en guerra con España, aliada a su vez con la Francia napoleónica. Derrotada en Trafalgar (I805), España perdió su supremacía naval, que a partir de entonces

3 Alternativamente mencionado con uno solo de sus nombres, como Manuel o Martín de la Calleja.

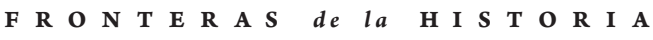

VOL. 24, N. ${ }^{\circ}$ 2. JULIO-DICIEMBRE DE 2019 
sería ostentada por los británicos. En aquel contexto bélico, al cual se sumaban los intereses comerciales de la entonces potencia naval hegemónica, Gran Bretaña intentó en dos oportunidades hacerse con el control del Río de la Plata, espacio clave del comercio colonial español en el Atlántico, que además de conectar los mercados peruanos con la metrópoli constituía un importante centro de contrabando (Socolow; Ternavasio).

Como hemos seńalado, los ofrecimientos de los caciques al Cabildo de Buenos Aires tuvieron lugar en los meses posteriores a la primera invasión, ocurrida entre el 27 de junio y el I2 de agosto de 1806 . A pesar de la inicial pasividad de las autoridades locales y de su población, durante la ocupación británica de la ciudad de Buenos Aires — que se extendió a lo largo de 46 días - se conformó una resistencia que organizó de forma secreta numerosos cuerpos voluntarios de milicia. Aunque la presencia de tropas regulares españolas era escasa, dichas milicias lograron hacer frente al ejército invasor con la ayuda de tropas llevadas a Buenos Aires desde Montevideo. También participó la población porteña y, luego de un encarnizado combate en el área de la plaza Mayor (actual plaza de Mayo, en el casco histórico de la ciudad), dichas milicias urbanas forzaron la capitulación del general William Beresford el I2 de agosto de I806. Esta derrota, sin embargo, no llevó a los británicos a abandonar sus ambiciones en el Río de la Plata; un año después emprendieron un nuevo intento de controlar la región. Esta vez tomaron primero Montevideo — cuya contribución había sido clave un año atrás para la reconquista de Buenos Aires—, aunque tampoco pudieron lograr su objetivo. Ambas invasiones tienen gran presencia en la memoria histórica local, desde que la propia plaza Mayor fue rebautizada como plaza de la Victoria, casi inmediatamente. En el espacio público, sendas calles del sector histórico de la ciudad — escenario de los enfrentamientos - llevan en la actualidad los nombres Reconquista y Defensa. Además, estos episodios forman parte de los contenidos escolares a escala nacional, recordados y celebrados como actos de patriotismo que prefiguraron el posterior proceso independentista.

Como ha apuntado Chiaramonte, en I806-I807 no existían aún propósitos independentistas ni una semilla de lo que sería la República Argentina posterior. Sin embargo, algunos autores, como Halperín Donghi y Gallo, han señalado la importancia de las invasiones inglesas como eventos que marcaron un quiebre en la realidad de la capital rioplatense. Las milicias urbanas creadas con ocasión de la primera invasión — con gran cantidad de soldados de origen criollo- se convirtieron en un nuevo actor político, una base de poder local para la élite criolla de comerciantes y burócratas del virreinato en notable ascenso (Halperín). 
Esa militarización porteña — que dio lugar a un poder castrense que no dependía de las tropas españolas - permitió la emergencia de una identidad más local, puso en evidencia la debilidad de España y fue clave para el proceso revolucionario que se abrió en i8ıo con la formación de una junta de gobierno en Buenos Aires, en sintonía con las de otros espacios peninsulares y americanos. En ese contexto, según señala un relato establecido, algunos caciques de los pueblos indígenas insumisos de la frontera sur de Buenos Aires ofrecieron ayuda militar al Cabildo de la ciudad para su defensa, a raíz de la primera invasión de i806.

Las publicaciones, tanto académicas como no académicas, en las que encontramos este relato se basan principalmente en los acuerdos de dicho Cabildo y afirman que esos caciques se presentaron en la sala capitular durante la segunda mitad de I806, en los días y meses posteriores a la recuperación de la ciudad de manos del ejército británico, para ofrecer soldados, armas, caballos y otros auxilios. Algunos han señalado que los caciques también ofrecieron la vigilancia de las costas, afirmación que, como veremos, debe ser matizada. Particularmente conocido es un discurso atribuido a los caciques, registrado en la sesión capitular del 22 de diciembre, por medio del cual habrían prometido 20.000 soldados indígenas, cada uno con cinco caballos. Asimismo, se señala que los cabildantes respondieron a estos ofrecimientos con agradecimientos y obsequios y aseguraron que los llamarían en caso de ser necesaria su ayuda. Por otro lado, el relato suele afirmar también que los caciques actuaban de modo espontáneo, movidos por un — supuesto- odio a los ingleses, a quienes denominaban "colorados". Sobre todo fuera de la academia, también se interpretan estos ofrecimientos como un acto patriótico por parte de los grupos indígenas de la región que no les ha sido suficientemente reconocido.

Numerosos autores se han referido a esta visita de los caciques, además de su circulación en espacios no académicos, como artículos periodísticos y blogs ${ }^{4}$, en particular alrededor del 2006 con motivo del bicentenario del episodio. Entre las publicaciones académicas, hay algunas muy antiguas, como las de Zerda,

4 Entre los artículos periodísticos, véase la nota de Héctor Cordero en La Prensa. Entre los blogs, “¿Ayuda indígena durante las invasiones inglesas a Buenos Aires?”, en https://histoaventura. blogspot.com/search?q=invasiones+inglesas, y "Los indios y las invasiones inglesas", en http:// historiasdecastelli.blogspot.com.ar/2012/03/los-indios-y-las-invasiones-inglesas.html. También en http://elarcondelahistoria.com/los-aborigenes-y-las-invasiones-inglesas-1806-2/. 
Molinari y L. Pérez`. Otros, como Hernández, se refieren a esta cuestión citando extensamente a esos primeros autores. Este ofrecimiento de ayuda militar de los caciques de la Pampa al Cabildo de Buenos Aires también ha sido señalado de modo reiterado en la bibliografía especializada más reciente. Algunos autores solo la mencionan (Mandrini, "Desventuras"; Roulet, Huincas) y otros la enmarcan en la tradición de acuerdos entre ambos actores de la frontera sur. Estos últimos la destacaron como una expresión de "la estrecha relación que se había logrado entre algunos grupos nativos y los vecinos de Buenos Aires en el periodo tardo colonial" (Ratto, 218), como el reconocimiento de los caciques indígenas — quienes en diciembre de I806 fueron al Cabildo "a felicitar a las autoridades españolas y a reafirmar su solidaridad con ellas" (Bechis, 4I) por las acciones de la reconquista de Buenos Aires-, o aun como prolegómenos a lo que luego sería el reconocimiento del primer gobierno patrio por parte de esos caciques 6 (Quijada). Sin embargo, tanto Bechis como Mandrini ("Las fronteras") y Martínez Sarasola (Nuestros paisanos, "El Mayo indígena”), este último desde la antropología, han hecho notar que resultaba muy poco posible que esos caciques reunieran el número de 20.000 guerreros que habían ofrecido.

Entendemos que este relato que hemos presentado constituye solo una de las narraciones posibles acerca de la propuesta de los caciques. En tanto aquello que se recuerda como el "pasado" no viene dado de una forma inmutable sino que es activamente compuesto desde el presente bajo la influencia de diversos intereses e intenciones (Connerton), en el ejercicio de traer el pasado al presente se habilitan múltiples modos de recuerdo y múltiples relatos (Ramos; Trouillot). El carácter situado de la construcción histórica —influida por su contexto-, como también la aplicación de mecanismos de selectividad, derivan en la producción de olvidos y silencios que otorgan características particulares a cada narrativa (Trouillot). Así, en la llamada "historia argentina”, este relato

5 También el precursor de la historia nacional argentina (Mitre) incluyó el tópico "patriotismo indígena" (167) en uno de los resúmenes de sus capítulos, aunque en el texto no se encuentran otras referencias a este episodio.

6 Algunos autores han señalado que uno de los caciques que visitaron el Cabildo en 1806 firmó luego un petitorio a favor de la destitución del virrey, entregado a ese cuerpo en mayo de i81o. Esta afirmación ha pasado de obra en obra sin referencias al documento que permitan corroborarla. Hace pocos años, el Museo Nacional del Cabildo y la Revolución de Mayo ha dado a conocer esa pieza, informando que se trató de un cacique limeño (véase https://es-la.facebook.com/cabildonacional/ posts/efem\% $\mathrm{C}_{3} \%$ A 9 rides-semanademayoel-petitorio-la-noche-del-24-de-mayo-de-i810-algunosmili/1656897527761907/). 
acerca del ofrecimiento de los caciques evidencia un desplazamiento desde la invisibilización de las sociedades indígenas — característica de la historiografía liberal—a cierto énfasis en su presencia y participación. Algunos de los trabajos arriba mencionados destacan el aporte de los indígenas a la conformación de la nación argentina (Bechis; Quijada). Es posible que esta línea argumentativa haya alentado en el público no especializado, como dijimos, la interpretación de los ofrecimientos registrados en los acuerdos como genuinos actos patrióticos que integran a los grupos indígenas a la historia de la patria por medio de un acto clave como lo fue la defensa de la ciudad frente a una potencia invasora. En este relato confluyen, así, dos grandes tópicos: el patriotismo indígena y la grandeza de la patria.

Sin embargo, esta intención de visibilizar la agencia indígena parece estimular ciertos sesgos en la lectura de las fuentes y la interpretación de los hechos, lo que lleva — en un juego de opuestos - a invisibilizar algunos indicios relevantes y desatender ciertos elementos del contexto. Así, la intención de cuestionar una construcción histórica (la ausencia de indígenas en la historia de la patria) puede llevar al establecimiento de otra (el patriotismo espontáneo de los grupos indígenas insumisos y su interés en la defensa de Buenos Aires). A continuación, proponemos desmontar y complejizar este episodio desde el análisis de sus protagonistas, los caciques de la Pampa que se presentaron en el Cabildo en I806, y del discurso que alguno de ellos pronunció en la sala capitular, tal como quedó registrado en las actas de esas reuniones. Atenderemos especialmente a la opacidad de los datos acerca de los pueblos indígenas que presentan en general las fuentes históricas, a los silencios y distorsiones del registro escrito que traduce deficientemente los compromisos orales que los caciques indígenas acordaban con la agencia colonial (Roulet, "Con la pluma") y a la evidencia de que ellos no fueron creados para responder a nuestras preguntas de investigación.

\section{Los actores y el contexto de las relaciones interétnicas en la frontera de Buenos Aires}

La larga tradición de relaciones pacíficas entre los grupos indígenas de la Pampa y los comandantes y pobladores de los puestos de frontera al sur de Buenos Aires implicaba acciones comerciales, tratados de paz, intercambios y diálogos diversos canalizados por medio de sus líderes o caciques. Existían acciones violentas desde uno y otro lado, como los malones y las incursiones punitivas, aunque 
para el momento que nos ocupa ambos tipos de ataques se habían moderado. Así, en los inicios del siglo Xix, aunque la frontera no había avanzado desde que se establecieron la mayor parte de sus puestos y guardias vecinos al río Salado en la década de 1770 (figura I), las relaciones entre los grupos indígenas y los hispanocriollos estaban más asentadas.

En este marco de relaciones pacíficas, se seguían estrictos protocolos que incluían regalos del lado español, permisos de paso por territorios propios del lado indígena y reciprocidades que ambos lados invocaban o prometían —incluyendo compromisos de defensa mutua-, en el marco de tratados de paz que tenían un formato bastante establecido (véase Tamagnini y Pérez). Entre las fuentes documentales de los puestos de la frontera sur hay infinidad de registros — desde mediados del siglo XVIII - acerca del paso de caciques con grupos de "indios y chinas" que se presentaban en ellos antes de dirigirse a Buenos Aires "a vender sus efectos" y luego regresaban en el término de cuatro a siete días, "regalados y satisfechos" de la amistad de los españoles (Nacuzzi, "Los grupos"). A pesar de esa asidua concurrencia de caciques y grupos a la ciudad, que se encontraba bastante pautada si pensamos en la existencia de lugares para su alojamiento (Mandrini, "Desventuras"), la presencia de estos personajes en la sala capitular durante las sesiones no fue habitual durante el siglo XviII (Acuerdos). Cuando tuvo lugar, los caciques siempre llegaron al Cabildo llevados o presentados por algún funcionario colonial, por lo que no se trataba de encuentros espontáneos. En toda la primera década del siglo XIX, las únicas visitas de caciques se produjeron en I806, luego de la primera invasión de los ingleses a Buenos Aires, para el ofrecimiento que nos ocupa.

Además de los puestos defensivos, en los bordes del espacio controlado por las autoridades coloniales habían comenzado a instalarse hacendados, como Manuel Martín de la Calleja, español de nacimiento, uno de los más importantes de Chascomús. Fue de los primeros estancieros en establecerse en la margen sur del río Salado, más allá de la frontera con los territorios indígenas tal como estaba conformada a fines del siglo xviri. Poblaba sus campos con el producto de su actividad como diezmero y se dedicaba también a la venta de ganado en pie y cuero (Galarza y Banzato). Este personaje fue el introductor del indio Felipe en la sala capitular en agosto de I806 y, muy probablemente, del cacique Catemilla unos días después. Sus vínculos con los puestos fronterizos de la región pampeana - y la estrecha relación de los incipientes hacendados con el dispositivo defensivo colonial — pueden apreciarse en un testimonio algo posterior a los hechos que nos ocupan. En agosto de i808, el comandante de 


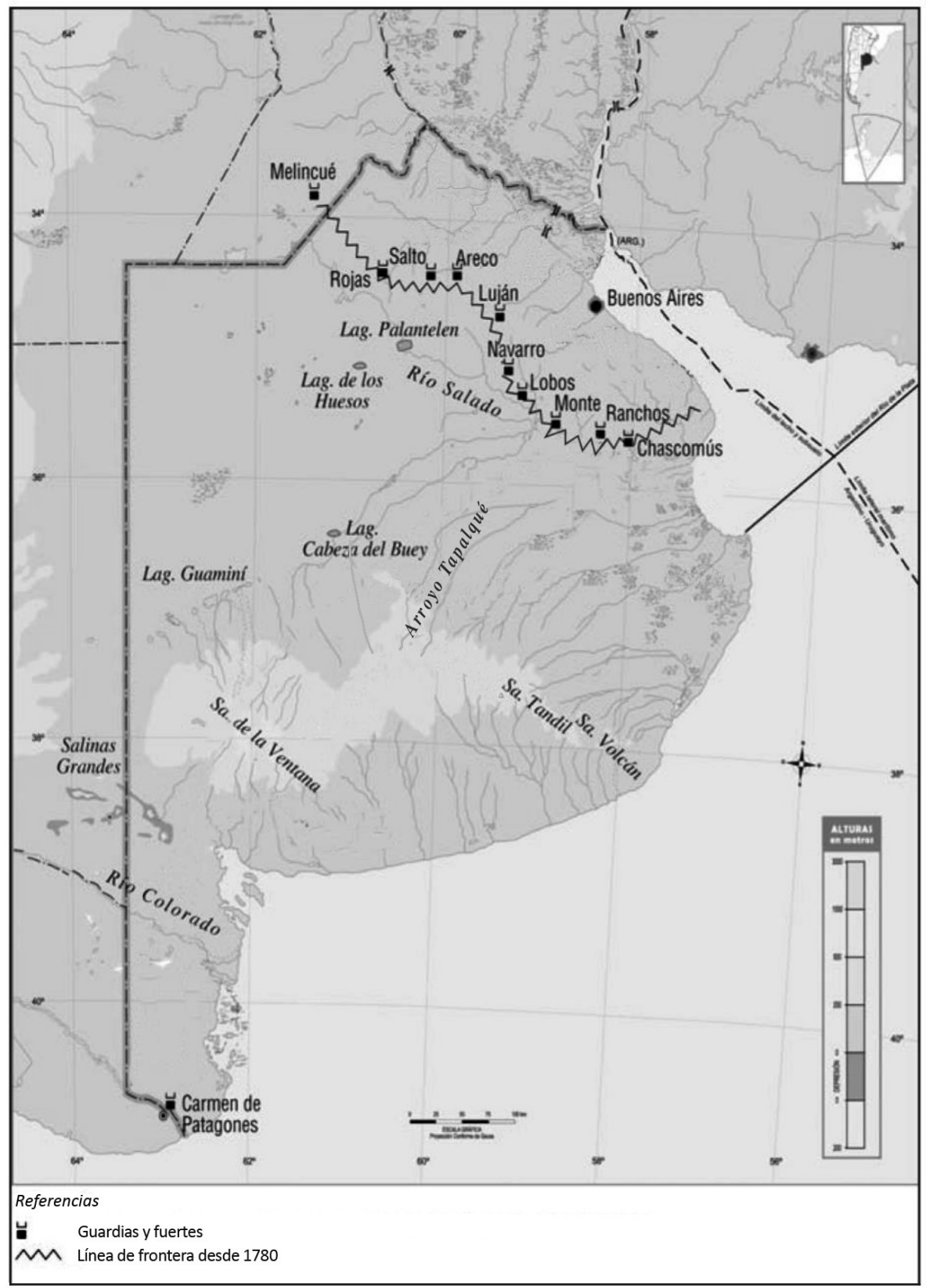

$\rightarrow$ FIGURA I.

Parajes y localidades mencionadas en el texto, con base en el mapa de Nacuzzi, "Los grupos"

Fuente: elaboración propia. 
la guardia de Chascomús, Juan Andrada, le informaba al virrey Liniers sobre el paso por esta - camino a Buenos Aires - de un cacique llamado Lucane, del río Negro. Este cacique había pedido especialmente que los acompañara a la ciudad un blandengue lenguaraz llamado Juan Manuel Luna, que al parecer trabajaba en la estancia de Manuel de la Calleja, por lo que "lo hice bajar [a Luna] de la estancia de Don Manuel de la Calleja, y mandé un miliciano en su reemplazo" (AGN, $S C$, IX I-4-3).

Según el informe al que nos hemos referido más arriba, el 8 de julio de 18067 Calleja fue enviado por el Cabildo a "las guardias de la frontera de la Magdalena, Chascomús, Ranchos, y el Monte" (ubicadas en el sector al sur de la ciudad ${ }^{8}$ ), y en ellas este comisionado había ubicado " 25 hombres y 2 oficiales para el reparo de la campaña”, probablemente con la intención de que no se extendieran los daños de la "pérdida de Buenos Aires" (AGN, $A C$, IX I9-5-5). Además, desde Chascomús, Calleja había enviado a Rafael Laudao — un cacique amigo que se hallaba "poblado con su gente" en su estancia - a la sierra de Tandil donde se encontraban dieciséis caciques pampas reunidos con su gente con motivo de estar en guerra con sus vecinos de la "nación ranquel". Rafael Laudao, enviado del enviado, iba con regalos — dos arrobas de yerba, ocho mazos de tabaco y dos piezas de cigarrillos- y el mensaje de que, tras siete años de trato en que le habían asegurado reiteradamente a Calleja su compromiso, "ahora era cuando solicitaba su verdadera amistad”. Según el mismo informe, cuando Calleja volvió al Cabildo, pasó — y le pagaron - la cuenta de los regalos que envió a los caciques en esa oportunidad. Luego regresó de nuevo a su estancia, [...] en donde encontré 3 enviados por aquellos caciques mis amigos, diciendo que inmediatamente de haber recibido mi enviado habían hecho paces con sus enemigos los ranqueles, y que para demostrarme sus fieles proposiciones me decían que si necesitaba de su gente y caballos les dijese cuanto gustase a sus chasques. (AGN, $A C$, IX I9-5-5)

7 Según esta fecha, la decisión de enviar a Calleja a la frontera fue tomada durante la ocupación inglesa - alrededor de quince días después de la invasión-, periodo en el cual el Cabildo de Buenos Aires no se estaba reuniendo, como podemos observar en los acuerdos, que pasan del 25 de junio al iz de agosto (Acuerdos).

8 Se ha podido reconstruir que las entradas de grupos indígenas a la ciudad estaban sectorizadas para los diversos caciques del sur y del oeste (Nacuzzi, "Los grupos”). 
Esos enviados de los caciques iban autorizados a negociar, por lo que Calleja decide: "bajaremos a Buenos Aires a tratar con el Cabildo por si acaso podíamos vernos libres de la polilla que se nos había entrado en la ciudad”. Uno de los chasques era el llamado indio Felipe, que se presentó en el Cabildo introducido por Calleja el I7 de agosto de I806, en nombre de los dieciséis caciques mencionados, quienes claramente no estuvieron presentes en la sala capitular en esa oportunidad. El informe afirma que el indio Felipe entró en la ciudad de Buenos Aires, acompañando a Calleja, el i2 de agosto a las tres de la tarde. No podemos confirmar la veracidad de esta sincronización con las acciones de la reconquista de la ciudad que culminaron exitosamente ese día, aunque sabemos que esa experiencia causó en el indio Felipe una impresión favorable para la ayuda que los españoles necesitaban:

[...] había visto en la plaza el día que entró muchos Colorados muertos, y a todos los demás maneados en el Cabildo y que a los dos días había ido [...] al fuerte y allí había visto muchísimos heridos, y después a donde los tenían encerrados con lo que, sus corazones se habían puesto muy grandes. (AGN, $A C$, IX 19-5-5)

Así, fue el indio Felipe quien, en nombre de los caciques, ofreció en esta primera visita al Cabildo "cuantos caballos y gente necesitase contra los enemigos de los cristianos esos Colorados que han venido a querer quitar nuestra tierra”. El Cabildo agradeció esta oferta de palabra y con otra vuelta de regalos (tres barriles de aguardiente y un tercio de yerba). Calleja detalló en su informe los pasos protocolares que siguieron estos enviados de los caciques al regresar: "llegados que fueron a sus tolderías dieron parte de su comisión, e inmediatamente se puso en camino uno de los I 6 llamado Catremilla a ratificar lo que el enviado había ofrecido" (AGN, $A C$, IX 19-5-5). Así, recién un mes más tarde, en una segunda visita, se presentó Catremilla o Catemilla en la sala capitular, el is de septiembre. Catremilla, Catemilla o Catrumilla aparece en otros documentos - que se produjeron en las guardias de Monte y de Chascomús cercanas a los campos de Calleja- por lo menos desde I802 hasta I809.

En efecto, ya en agosto de 1802 este cacique reclamaba, en la frontera de Monte, que el virrey "se digne hacerle los obsequios acostumbrados, a los legítimamente de su clase" (AGN, $S C$, IX I-4-6) y luego, en junio de I803, no solo se le había extendido un pasaporte en el fuerte de Chascomús (AGN, $S C$, IX I-4-3) para que se dirigiera a Buenos Aires a visitar al virrey (figura 2), sino que era considerado cacique pampa amigo "por tener sus toldos con bastante inmediación 
a los fuertes" de Chascomús y Ranchos (AGN, $S C$, IX I-4-3). En septiembre de I809 se reitera la condición de amigo de Catrumilla casi en los mismos términos y destacando la larga relación con las autoridades de la capital del virreinato:

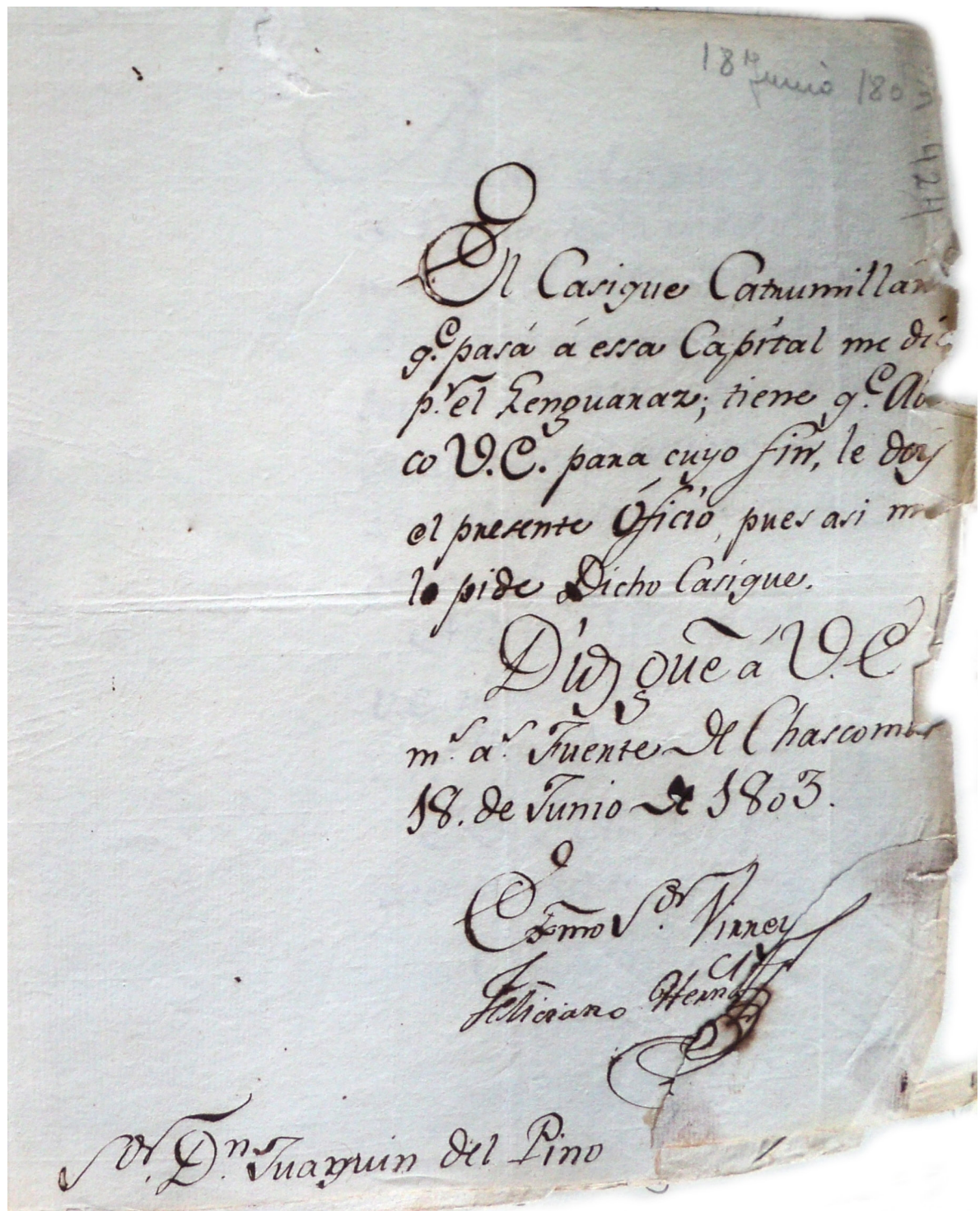

$\rightarrow$ FIGURA 2.

Pasaporte otorgado al cacique Catrumilla, I8 de junio de 1803

Fuente: AGN, SC, IX I-4-3. 
Se ha presentado en esta frontera el cacique nombrado Catrumillan. Pasa a esa Capital con el objeto de presentarse a V[uestra] E[xcelencia] y con el de entablar y ajustar las paces y prometer la amistad y armonía, que ha prometido y conservado con los antecesores de V[uestra] E[xcelencia]. Según tengo entendido es cacique de respeto y mucho séquito entre los Indios Pampas. (AGN, SC, IX I-4-6)

En la sala capitular, el is de septiembre de i806, Catremilla/Catemilla ratificó la oferta de gente y de caballos y expresó que solo para estar a la altura de las circunstancias (de las urgencias que vivían los cristianos) había hecho las paces con los ranqueles y, a la vez, les había impuesto la tarea de "guardar los terrenos desde las Salinas hasta Mendoza, e impedir por aquella parte cualquier insulto a los cristianos" (Acuerdos 303). Del mismo modo, el cacique expresaba que él, junto con "los demás Pampas", se comprometía "a hacer lo propio en toda la costa del sur hasta Patagones" (Acuerdos 303). Los cabildantes volvieron a agradecer y a disponer regalos, encomendando a Calleja "que lo gratificara con yerba y aguardiente pasando la cuenta al mayordomo de Propios para su abono" (Acuerdos 304). No podemos afirmar que esta división étnico-territorial no haya sido adjudicada por los cabildantes, por el escribano o por los lenguaraces, de acuerdo con sus conocimientos previos acerca de los grupos indígenas. Recordemos que las expediciones a las Salinas se realizaban regularmente una vez por año, desde hacía por lo menos siete décadas (Taruselli; Nacuzzi y Tourres), y el trato con los caciques de la región había tenido lugar desde el momento mismo de la fundación de la ciudad de Buenos Aires en el siglo XVI. Así, esta primera etapa de visitas de caciques al Cabildo fue protagonizada por uno de los líderes reconocidos por las autoridades de Buenos Aires desde varios años atrás, considerado indio amigo, inserto en los tratos y reciprocidades que implicaban los acuerdos de paz, que a la vez tenía contacto bastante asiduo con uno de los hacendados de la frontera sur.

Luego, en diciembre de ese mismo año de I806, tuvo lugar otra serie de visitas de caciques al Cabildo, entre los días 22 y 29. En esa oportunidad, el día 22 se presentaron "diez caciques de estas Pampas", ofrecieron "hasta el número de veinte mil de nuestros súbditos, todos gente de guerra y cada cual con cinco caballos" (Acuerdos 363) y pronunciaron el conocido discurso que ha sido mencionado reiteradamente en la bibliografía, a lo cual los cabildantes contestaron a su vez con otro discurso, agradecimientos y obsequios (véase anexo). En el acta de ese día, 22 de diciembre, no se consignaron los nombres de los diez caciques; 
suponemos que los que estuvieron presentes fueron los que luego se listaron en el acta del día 29: Chulí Laguini, Paylaguan, Cateremilla, Negro, Marciúús, Lorenzo, Guaycolam, Peñascal, Luna y Quintuy. Dice el acta de ese día: Avisó el portero que los caciques capitanes Epugner, Errepuento, y Turuñamquü pedían permiso para entrar; y habiéndoseles franqueado tomaron asiento y expusieron por intérprete que instruidos por los caciques pampas capitanes Chulí Laguini, Paylaguan, Cateremilla, Negro, y por los caciques Marciúús, Lorenzo, Guaycolam, Peñascal[,] Luna, Quintuy del mucho agasajo que había hecho este Cabildo a sus personas, y agrado con que había admitido sus ofertas; querían manifestar del mismo modo los deseos que tenían de ayudarlo contra los colorados o ingleses. (Acuerdos 373)

Como observamos, Epugner, Errepuento y Turuñamquü actuaron en representación de diez caciques que no regresaron al Cabildo. Se presentaban porque querían realizar sus propios ofrecimientos. También el informe de Calleja consigna: "El 29 presenté al cacique Capitán Epugner quien dijo era de la costa de Valdivia [...] estaban sus dos compañeros hermanos Errepuento y Turuñamen" (AGN, $A C$, IX I9-5-5). A mbos registros, el informe y el acuerdo, señalan que Epugner manifestó que tenía 2.862 de sus soldados — "gente de guerra bien armados de chuza, espada, bolas, y onda con sus coletos de cuero"- en Cabeza del Buey, un conocido lugar de la frontera sur que era utilizado por los hispanocriollos como paraje seguro y punto de regreso de las expediciones a las Salinas. Por su parte, los otros dos caciques - Errepuento y Turunamqü̈- ofrecieron "siete mil de sus soldados que mantenían en Tapalquen armados como los anteriores" (Acuerdos 373). Estos parajes se encontraban a unos $300 \mathrm{~km}$ al sudoeste de la ciudad de Buenos Aires, por fuera de la línea de fuertes y guardias, y eran considerados territorio indígena en ese momento.

Es notable que, en el acta del 29 de diciembre, algunos de los líderes indígenas sean llamados "caciques capitanes" y otros solamente "caciques", quizás para identificar a los que ofrecían tropa con hombres armados. En total estos trece líderes habían prometido casi 30.000 soldados. Como dijimos, Bechis y Mandrini ("Las fronteras") han manifestado dudas acerca de tal número de guerreros disponibles. Es un número ciertamente notable, aunque si se lo considera desde una perspectiva regional es posible que - como afirma la primera autora - se hubieran podido reunir, considerando las fuerzas de guerra de araucanos y tehuelches. También es probable que los caciques, en sus discursos 
protocolares que reafirmaban su amistad y compromiso hacia los españoles, hayan mencionado esas cantidades retóricamente para enfatizar su influencia y poder de convocatoria. Si esa fue la intención, lograron impactar a los cabildantes quienes les manifestaron que "la fidelidad, amor, y patriotismo de las numerosas y esforzadas tropas que en cuerpos se hallan formadas, aseguran la defensa de esta hermosa Capital" y les solicitaron que, en cambio, se ocuparan de vigilar las costas, en referencia a las del norte de la Patagonia (Acuerdos 364). Parece verosímil que los cabildantes se hayan preocupado por un número tan alto de guerreros indígenas aprestados para la defensa, aunque la misión de cuidar las costas no constituía solo una maniobra de sustitución para los objetivos bélicos de los caciques. Para la administración colonial española, la Patagonia y especialmente sus costas eran una preocupación reiterada acerca de una posible invasión de potencias extranjeras; desde 1774 el peligro había parecido más cierto dada la publicación de la conocida obra del jesuita inglés Thomas Falkner, y eso había dado como resultado la reactivación de los planes defensivos de la Corona para el Río de la Plata, que implicó la creación de fuertes en las costas patagónicas, como Nuestra Señora del Carmen de Patagones en 1779. La fecha coincidió con la instalación de varios fuertes en la frontera sur de la ciudad de Buenos Aires, entre ellos el de Chascomús en ese mismo año. En esos puestos defensivos la interacción de sus comandantes y pobladores con los grupos y caciques indígenas era muy intensa, como referimos más arriba, lo que resultó en intercambios — de bienes, servicios, mensajes, cautivos, ganados, objetos simbólicos - propios de un espacio fronterizo dinámico y cambiante.

Acerca de la pertenencia étnica de los caciques que se presentaron en el Cabildo, señalamos que, tanto en los acuerdos como en otras fuentes de la región y el momento, son nombrados reiteradamente como pampas. Además, en la primera de las actas citadas (del I7 de agosto de I806) se los nombró como de los pampas y tehuelches (escrito "cheguelchos"). Por más que "pampa" sea un etnónimo basado en la ubicación geográfica de estos grupos, debemos reconocer que, para el momento que estamos analizando, ese nombre tenía una atribución también política y cultural. Se trataba de grupos que efectivamente habitaban en la Pampa y que probablemente tuvieran parientes y lazos políticos con los mapuches de Chile, aunque también los tenían con los llamados aucas en ese momento (mapuches que habitaban la Pampa), con los ranqueles de las Salinas (considerados aucas algunas veces) y con los tehuelches de más al sur (del norte de la Patagonia). Todos estos grupos eran cazadores nómades o pastores y no restringían sus actividades económicas a territorios fijos; antes bien, 
las complementaban mediante movimientos estacionales organizados para el comercio o el intercambio entre ellos y con los hispanocriollos de los fuertes y ciudades vecinas (Nacuzzi, Identidades). Por esto, la bibliografía especializada se ha enfocado reiteradamente en la definición de sus posibles territorialidades. En este sentido, las actas del Cabildo permiten reconocer dos regiones bastante nítidas: la de las Salinas y la de la costa patagónica, esto es, al sudoeste y al sur de la capital del virreinato. Estas dos regiones no solo son mencionadas por quienes registraron los acuerdos; también los caciques presentes se identificaron con ellas. Catemilla se presentó como delegado de dieciséis caciques de la Pampa, y como tal envió a Felipe - quien se hizo presente en el Cabildo el I7 de agosto-; luego concurrió en persona el is de septiembre, para regresar más tarde acompañado por otros nueve caciques el 22 de diciembre. Como dijimos más arriba, este líder indígena era conocido en diversos puestos de la frontera y también tenía amistad con Manuel de la Calleja, el enviado del Cabildo.

Entre los otros caciques que acompañaron a Catemilla se puede identificar - a pesar de las cambiantes grafías - a algunos otros que también tenían contactos previos con los funcionarios hispanocriollos. Son los casos de Chulí Laguini (que puede leerse como Chulilaquin), Negro y Lorenzo. El primero había tenido fluida relación con el fuerte de Carmen de Patagones desde su

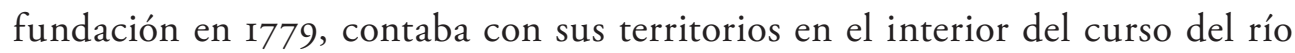
Negro, como se registró repetidamente en las fuentes documentales, aunque en esas últimas décadas del siglo xvin bajaba regularmente a su desembocadura — donde se hallaba ese fuerte- y también se dirigía a los campos de Buenos Aires para apropiarse de ganado (Nacuzzi, Identidades). Negro fue el cacique de esos parajes que permitió la instalación del mencionado fuerte y acaparó las primeras interacciones con Francisco de Viedma y los demás funcionarios fundadores. Según Crivelli ("Malones"), Negro falleció antes de diciembre de I786; el que asistió al Cabildo podría haber sido su hijo, si atendemos al registro del fuerte de Chascomús que señala que en noviembre de 1790 se había presentado: "una partida de indios de la Nación Peguelchus y se compone del hijo del cacique Negro cinco indios y dos chinas", que llegaban quejándose de Lorenzo y de los "de Nación Aucas" y afirmando que a ellos les correspondía la región de las costas patagónicas (AGN, $S C$, IX I-4-3). Podemos observar aquí la misma territorialidad — reclamada o atribuida en los Acuerdos - para Negro y, también, que Lorenzo y Negro llevaban una larga relación cuando se presentaron en el Cabildo. Señalamos, además, que había existido un cacique llamado 
Lorenzo Callfilqui o Calpisqui — que tenía sus tolderías en sierra de la Ventana (Nacuzzi, Identidades) - y había fallecido en 1796 (Crivelli, "Pactando").

Acerca de los tres caciques que se presentaron el 29 de diciembre, observamos que no son identificados en los Acuerdos respecto de su grupo étnico de pertenencia; sin embargo, también eran conocidos, porque diversas expediciones a Salinas los habían contactado previamente y lo seguirían haciendo. Epugner (o Epumer) y Errepuento (o Gurupuento) aparecen mencionados juntos en numerosas ocasiones. Por ejemplo, en Cabeza del Buey —el mismo paraje donde el primero afirmaba tener listos los guerreros que ofrecía - habían ayudado al comandante de la expedición a Salinas de 1803 a buscar a uno de sus oficiales que se había perdido: "infiero haya perecido respecto de no haberlo encontrado los indios de los caciques Epumur, y Gurupuentù mis antiguos amigos en cuyas inmediaciones desapareció" (AGN, $S C$, IX I-4-2). También, en marzo de I805 se registraba su paso en la guardia de Luján:

Antes de ayer entraron a esta frontera los caciques de nación pampa Epomur, y Nerupuentru, y hoy salen de ella para esa Capital con el fin de presentarse a VE en cumplimiento de haberlo así prometido al Primer Comandante del cuerpo de que dependo en la última expedición que se hizo a Salinas; y lo aviso a VE para su superior inteligencia. (AGN, $S C$, IX I-7-I)

Luego de instalada la primera Junta de Gobierno en Buenos Aires, en I8Io, el coronel Pedro Andrés García fue enviado a las Salinas donde se entrevistó con estos y otros caciques de la región. Roulet (Huincas 339) ha analizado cómo los identificó ese expedicionario: Epumur tenía dos hermanos, con los cuales se habían instalado "en puntos nodales de la ruta que unía" Valdivia con Buenos Aires; a su hermano Victoriano le correspondió el territorio cordillerano; a otro hermano llamado Quinteleu, los parajes de las Salinas, y al propio Epumur, la región de la laguna Cabeza del Buey. En esos parajes los caciques se asociaron "con caciques locales [...] creando una vasta red de alianzas políticas, militares y comerciales”. Turuñamquü o Turuñan era un vecino de Gurupuento, según lo registraron Pedro García en I8ro y otros expedicionarios a las Salinas, como Juan Ignacio Terrada, en I808. Al salir esa expedición, como era costumbre, su comandante avisaba a la guardia de Luján que: "le acompañan los caciques Lincon, Turuñan, Enec, Epuentu, su hijo, Oquin, Ancaya, y Añapi, que le han vendido muchas lisonjas, y bebido mucho aguardiente" (AGN, $S C$, IX I-7-I). Como 
varios de los nombrados hasta aquí, Turuñan tenía una sólida amistad con los hispanocriollos, por lo menos desde i8or:

El cacique Turuñan, hijo del finado nombrado Catrué, uno de los que más se distinguieron en establecer la actual paz, se traslada en esta ocasión a esa Capital a la venta de sus acostumbrados efectos, y con la mira de mostrar a V[uestra] E[xcelencia] la buena fe e inclinación que nos profesa, cuya noticia me pide dé por mi parte a V[uestra] E[xcelencia] como desde luego lo verifico para su superior conocimiento. (AGN, $S C$, IX I-6-6)

Como hemos mostrado, entre Buenos Aires y los grupos indígenas de las Salinas y de las costas patagónicas ya existía desde bastante tiempo atrás una relación asentada y cuidada por diversos mecanismos de intercambio - de bienes, de cautivos y de objetos simbólicos- y tratados de paz. En ese contexto, sostenemos que los caciques que se presentaron en la sala capitular lo hicieron para expresar su respeto a esa tradición y, sobre todo, siguieron la rutina habitual de los acuerdos que el representante del Cabildo les había reclamado previamente: manifestaron que los ranqueles de las Salinas estaban en guerra con los de la Pampa, y que habían decidido interrumpir esa guerra porque los líderes de ambos grupos atendían a la amenaza externa a las autoridades del virreinato español y decidían colaborar con ellas. Así, acordaron entre ellos que los ranqueles se ocuparían de resguardar la región del oeste, "los terrenos desde las Salinas hasta Mendoza” (Acuerdos 303), y los pampas irían a vigilar y defender la costa patagónica, unos espacios que formaban parte de sus territorialidades habituales.

\section{Los caciques en la sala capitular: el discurso del 22 de diciembre}

En el acuerdo del 22 de diciembre de 1806 encontramos un discurso atribuido a diez caciques de la Pampa, muy conocido y ampliamente difundido, muchas veces separado de su contexto de producción. Esto es posible debido a que se encuentra citado en estilo directo (sin comillas, pero introducido por dos puntos), de modo que puede ser identificado como una unidad y, eventualmente, extraído del texto más amplio del acuerdo en el que se inserta. Aunque en algunas obras 
aparece como una transcripción literal ${ }^{9}$, debemos recordar que las palabras de los caciques no fueron registradas de modo directo. Si bien todas las voces presentes en los acuerdos del Cabildo de Buenos Aires se encuentran mediadas por la pluma del escribano ${ }^{10}$, más lejana aún resulta la representación de las voces y el accionar indígena sujetos a una doble mediación, ya no solo del escribano sino también del lenguaraz que permitía la comunicación entre dos universos lingüísticos distintos (Nacuzzi y Tourres).

Consideramos, como señala Blommaert, que resulta imposible prescindir del contexto extralingüístico de un discurso. En tanto las circunstancias históricas, sociales, culturales, políticas y económicas pertenecen a sus condiciones de producción, el discurso se encuentra siempre orientado por los objetivos de un sujeto locutor — colectivo o individual—, atravesado por intereses particulares, de modo que nunca es neutral. En tal sentido, el contexto de producción de estos acuerdos resulta clave en cuanto la relación asimétrica entre hispanocriollos e indígenas - y los intereses muchas veces opuestos de ambos grupos- tenía una importante influencia sobre el contenido de los registros escritos. Así, era el escribano quien ponía palabras en boca de los caciques - y los intérpretes- y delineaba el contenido de los discursos que les fueron atribuidos. Esto muestra una gran desigualdad de voces, que debemos analizar con una mirada que atienda al efecto de ventriloquía (según la expresión de Guerrero) por medio del cual se presentaron los intereses - y los discursos- propios de la agencia colonial como propósitos de la parte indígena.

Antes de referirnos al discurso en sí mismo (véase anexo), señalamos que en estos acuerdos los grupos indígenas insumisos del sur aparecen identificados de modo concreto, mediante etnónimos (pampas, ranqueles, cheguelchos) y nombres particulares (Felipe, Catemilla, Negro, Lorenzo, entre otros). Ello se debía al carácter administrativo y local del contexto de producción de estos documentos: el Cabildo de Buenos Aires, cuya jurisdicción y funciones se referían a su realidad circundante más inmediata, por lo cual sus integrantes -y autores de los acuerdos - trataban con dichos grupos indígenas cotidianamente. Asimismo, resulta interesante notar dos características del modo en que este texto introduce a los actores indígenas. Leemos: "En este estado se avisó por el portero que diez caciques de estas Pampas pedían permiso para entrar en la sala,

9 Por ejemplo, Bechis cita de Puiggrós una versión libre (o adaptada) de este discurso, que no es estrictamente fiel al registro que encontramos en el acuerdo del 22 de diciembre.

I0 Para un análisis de las distorsiones introducidas en este tipo de registro, véase Nacuzzi y Tourres. 
y habiéndolo obtenido entraron, tomaron asiento y arengaron por medio de intérprete en la forma siguiente [...]" ${ }^{\text {II }}\left(\right.$ Acuerdos 362) ${ }^{\text {I2 }}$. En primer lugar, resulta notorio que los caciques hayan "pedido permiso" para ingresar a la sala por medio del portero, en lo que parece una acción espontánea que implicaría una amplia accesibilidad al Cabildo. Más bien, en otras visitas registradas en los acuerdos los indígenas son siempre llevados y presentados por algún funcionario o personaje hispanocriollo especialmente designado para ese fin. Sí podemos observar que los caciques cumplieron con un ceremonial de ingreso a la sala. En segundo lugar, observamos cómo en el acuerdo se introduce el discurso utilizando la figura de la "arenga", lo cual puede remitir a la efusividad de la alocución o bien a la intención de describirla de ese modo para generar dicha imagen.

Un elemento de este discurso que se destaca especialmente - y a partir del cual es conocido y mencionado habitualmente- es su fórmula de inicio, ya que comienza dirigiéndose "A los hijos del Sol". Ciertamente, a primera vista resulta llamativo encontrar esta expresión — que, como señala Bechis, era utilizada para dirigirse al emperador inca- en un discurso de los caciques hacia los cabildantes. Aunque lo más probable es que se trate de palabras puestas en boca de los caciques por la pluma hispanocriolla —el efecto de ventriloquía que hemos descrito más arriba-, su utilización resulta en principio opaca. Sin embargo, esta invocación se refiere seguramente a los hijos de los monarcas españoles, quienes sobre todo desde el reinado de Carlos III habían promovido este tipo de simbología (M. Pérez). Más adelante, en I8ı6, la cuestión de un rey inca para el sistema de gobierno que decidían los congresales de las Provincias Unidas del Río de la Plata sería objeto de discusión en diversos ámbitos políticos del momento (y, en la actualidad, motivo de estudio por parte de los que investigan el momento inicial de la nación argentina, como Tourres). Utilizada en I806, esa fórmula ciertamente no se refiere a los incas.

Por otro lado, las herramientas del análisis discursivo ${ }^{13}$ nos permiten indagar acerca de los modos de construcción o representación de los interlocutores, tanto en el discurso atribuido a los caciques ${ }^{14}$ como en la respuesta de los cabildantes,

II A continuación, el texto cita el discurso de los caciques en estilo directo.

I2 Todos los destacados de este apartado son nuestros.

13 Particularmente, observamos la construcción de grupos por medio del uso de pronombres (nosotros, vosotros) e identificamos la presencia de la subjetividad del enunciador, presente en los vocativos y calificativos utilizados (Kerbrat).

I 4 Es posible que el escribano haya compendiado en un único discurso las palabras de varios de los visitantes, en un efecto de "construcción compuesta" (Davis). 
ambos registrados por la pluma del escribano. El discurso de los caciques se construye a partir de la clara delimitación nosotros-vosotros. El "nosotros" utilizado por los caciques, que excluye a los interlocutores (nosotros exclusivo), se distingue del "vosotros" que designa a los cabildantes - y probablemente a toda la sociedad hispanocriolla por extensión-: "venimos personalmente a manifestaros nuestra gratitud", "Hemos querido conoceros por nuestros ojos" (Acuerdos 362-363). El término utilizado para referirse a los invasores también marca la diferencia entre ambos grupos. La respuesta de los cabildantes señala: "los ingleses nuestros enemigos y vuestros[,] a quienes llamáis colorados (Acuerdos 364). La injerencia del escribano se puede observar en la utilización de expresiones que intentan construir un acercamiento entre ambos grupos. El hecho de que el discurso atribuido a los caciques presente conceptos europeos que indican respeto y deferencia, tales como "nuestros Reyes" y "vosotros que sois los Padres de la Patria” (Acuerdos 362) expresaría - en la perspectiva del escribano como funcionario colonial— una identificación de los caciques con la monarquía española.

Esos vínculos entre los indígenas pampeanos y los hispanocriollos porteños se pueden apreciar también en las referencias a las relaciones comerciales que los unían, y que requerían como signo de reciprocidad que los caciques ofrecieran auxilios y recursos para la defensa de la ciudad frente a los "colorados": "nuestro reconocimiento en la buena acogida que dais a nuestros frutos, y permiso libre con que sacamos lo que necesitamos es lo bastante a recompensaros con este pequeño servicio" (Acuerdos 363). La respuesta de los cabildantes, según leemos en el acuerdo, aparece imbuida de la misma amabilidad y complacencia que las palabras atribuidas a los caciques, puesto que destaca el "gozo" generado por el afecto y el reconocimiento recibido de parte de los caciques, así como la fidelidad con la que se ofrecían a defender los dominios de "sus Soberanos que tanto los ama y recomienda" (Acuerdos 363).

Por último, el discurso de los caciques finaliza afirmando: "[sus propios súbditos] a una voz claman por vuestra felicidad [la de los cabildantes], que deseamos sea perpetua en la unión que os juramos" (Acuerdos 363), lo cual podemos interpretar como expresión de respetuosa sumisión (al jurar la unión) y, a la vez, de horizontalidad (en la unión misma), que se haría extensiva a la sociedad que esos cabildantes representaban. Los cabildantes, por su parte, 
responden también en los dos posibles sentidos. Por un lado, aseguran "protección” a cambio de sus ofrecimientos, refiriéndose a lo que la Corona —o el gobierno, mencionado con diversos nombres - les "otorga" regularmente; por el otro, aceptan la unión que los caciques les juran y los "abraza[n] como a fieles hermanos" (Acuerdos 363). Sobre todo en esta última expresión observamos una actitud asociada a una reciprocidad o alianza de carácter horizontal.

Además de señalarles a los caciques que su intervención no era necesaria debido a la presencia de nuevos cuerpos de milicia en Buenos Aires, hemos señalado que el Cabildo les "recomienda [...] el celo y vigilancia de nuestras Costas" (Acuerdos 364). Aquí, hay que matizar la lectura habitual sobre este episodio que indica que los caciques ofrecieron controlar y vigilar las costas patagónicas (Ratto). Martínez Sarasola (Nuestros paisanos, "El Mayo indígena”) directamente afirma que grupos indígenas, debidamente escondidos, espiaron los movimientos de los británicos recién desembarcados. Más bien, en las palabras de los cabildantes podemos reconocer el intento de enunciar como propios espacios sobre los cuales no tenían control efectivo ("nuestras Costas") y que en realidad formaban parte de la territorialidad indígena, hecho bien conocido por los funcionarios coloniales.

Si se observa la escena evocada por este discurso, en su conjunto, podemos reconocer, como señalamos más arriba, las características de un encuentro diplomático. Los tratados de paz o la presentación de grupos indígenas en los puestos de la frontera, por ejemplo, seguían una lógica particular que incluía el envío previo de emisarios, la presentación ceremonial de los caciques (saludos, discursos), la realización de ofrecimientos o el establecimiento de compromisos de ambas partes y el cierre con agradecimientos, reconocimientos y obsequios (Nacuzzi y Lucaioli). Esa fue la rutina que se siguió en estos encuentros de I806 en la sala capitular, en los cuales predominó el trato horizontal antes que la configuración vertical asociada con la dominación o el paternalismo, que era más común en los vínculos con otros grupos indígenas de ese periodo en otras regiones.

\section{Consideraciones finales}

Para el episodio de la presentación de los caciques de la Pampa en la sala del Cabildo de Buenos Aires, durante la segunda mitad de I806, pueden adoptarse diversas perspectivas de análisis. Una de ellas enfocada en las relaciones diplomáticas de los funcionarios coloniales con los caciques indígenas; otra 
—en tensión con la anterior-, en la incorporación de los pueblos indígenas al discurso sobre los prolegómenos de la independencia nacional, y una tercera que atienda a la crítica y análisis de las fuentes históricas disponibles.

El episodio da cuenta de una larga rutina de relaciones políticas entre esos caciques y la agencia colonial, representada hasta ese momento casi exclusivamente por sus funcionarios. En efecto, conocemos ampliamente cómo se relacionaban estos grupos indígenas y sus caciques con los comandantes de los fuertes de la línea sur, con diversos oficiales y tropas destinados a realizar expediciones punitivas o de reconocimiento del territorio, con delegados de las autoridades que iban a pactar acuerdos de paz y, también, con los cautivos hispanocriollos que pasaban periodos de diversa duración en las tolderías de tierra adentro. En cambio, sabemos muy poco de las interacciones de esos mismos caciques y grupos con los hacendados que habían comenzado a instalarse en esas tierras, de los que Manuel Martín de la Calleja parece ser un ejemplo pertinente. En este sentido, señalamos que podrían ubicarse otros testimonios de este tipo de relación, que sin dudas permanece poco explorada.

Como dijimos, la presencia de caciques en el Cabildo era excepcional, y así se puede verificar rápidamente explorando los índices de los Acuerdos. Además, al repasar los nombres de los líderes presentes en la sala capitular en esos meses de I806, pudimos obtener un panorama de las territorialidades que ellos invocaban y las que los cabildantes les atribuían, como resultado de una larga experiencia previa acumulada por las autoridades coloniales. Del reconocimiento de dichas territorialidades por una y otra parte, se desprendía el compromiso de controlar esos espacios para los grupos indígenas: el sector de las Salinas al sudoeste de Buenos Aires sería controlado por los ranqueles; el sector de la costa atlántica, al sur de la ciudad, por los pampas. Considerado desde el punto de vista regional, el espacio comprometido era muy vasto y comunicaba a la Pampa con la Araucanía y con el norte de la Patagonia. Mirada desde esta perspectiva, la oferta de casi 30.000 guerreros por parte de los caciques pierde su cariz de exageración retórica. Los caciques acudían a defender a sus amigos cristianos que se encontraban en problemas y no dudaban en ofrecer el máximo de sus posibilidades. Es muy probable que la primera visita del cacique Catemilla al Cabildo no haya ocurrido como una iniciativa propia sino producto de su amistad con Calleja, que había instalado su estancia en tierras cercanas a las de ese líder indígena. Catemilla, primero, y luego los demás caciques desplegaron todas las regulaciones de una acción diplomática de acuerdo con la tradición de esos pactos: oferta de guerreros y transporte, compromiso 
de cuidado territorial, retórica sobre la valentía y la pertenencia a una misma nación. Siguiendo el mismo canon, también recibieron agradecimientos, reconocimientos simbólicos y obsequios en bienes valorados. Todo ello contenido en discursos de una y otra parte.

Sobre el discurso que se transcribió a los Acuerdos, podemos decir que se identifica en su registro una doble mediación: la del lenguaraz actuante — que aparece bajo la fórmula "expuso por intérprete" - y la del escribano que aparece bajo la fórmula de cierre del acta "de que doy fe". Luego, destacamos que no tenemos ninguna posibilidad de deslindar ni de identificar estas injerencias —que responden más a los intereses de los cabildantes que a los de los líderes indígenas - en el texto del discurso. Solo podemos señalar que seguramente existe una lectura sesgada por parte de los cabildantes, una mirada de hombres de ascendencia europea, tanto para el discurso como para las acciones defensivas que proponían los caciques. A estas posibles distorsiones hay que sumar la que responde a una lectura meramente literal que se ha hecho de estos episodios, más de un siglo después de transcurridos, por parte de los especialistas. En el marco más estricto del análisis discursivo, señalamos la construcción básica de un nosotros-caciques (exclusivo) frente a un vosotros-cabildantes-hispanocriollos, a partir de la cual se marcan diversos acercamientos entre ambas partes. La actitud de deferencia y respeto propia de la diplomacia entre naciones constituye el marco de reciprocidad más amplio en el que se realizaron los ofrecimientos. Sin embargo, ambas partes, hacia el final de sus intervenciones, hicieron referencia a una unión, que puede ser interpretada tanto en clave de sumisión-protección como de hermandad-horizontalidad, que resulta más afín a un discurso inclusivo en una misma unidad política.

Los acuerdos o actas del Cabildo han sido las fuentes históricas utilizadas casi excluyentemente para reseñar e interpretar este episodio. El contexto de la gesta del movimiento independentista hace bastante difícil el acceso a los escritos originales en la actualidad. La posibilidad misma de revisar el relato establecido se debió a la ubicación —en el archivo del Cabildo- de un corto informe de Manuel Martín de la Calleja, enviado por ese cuerpo a los puestos de la frontera sur mientras ocurría la primera invasión inglesa. Así, tuvimos la posibilidad de comparar y complementar ambos registros, el del informe y el de las cuatro actas del Cabildo que manifiestan la presencia de caciques en la sala capitular entre agosto y diciembre de I806, a lo que se sumaron otros registros de la documentación de la Comandancia de Fronteras que dan cuenta del paso de varios de esos caciques por los puestos defensivos. Dada la correspondencia de fechas 
y eventos entre estos tres tipos de registro, pudimos devolverles cierto espesor histórico a los hechos relatados tan reiteradamente, que en muchas ocasiones aparecen presentados de manera sincrónica o descontextualizados: el accionar de Calleja en la frontera, los aspectos ceremoniales de la presentación de los caciques, los diferentes conjuntos de caciques que se presentaron en cada sesión en la sala capitular, los compromisos que asumieron en cuanto al control de los espacios fronterizos, las circunstancias de cada visita — que incluía interacciones previas de larga data-, los ofrecimientos que manifestaron y las construcciones discursivas que se esgrimieron, todo ello enmarcado en una acción diplomática entre los funcionarios coloniales y los líderes indígenas.

\section{8 \\ B I B L I O G R A F í A}

\section{F U E N T E S P R I M A I A S}

\section{A. Archivos}

Archivo General de la Nación, Buenos Aires, Argentina (AGN).

Sección Archivo del Cabildo (AC), sala IX, 19-5-5.

Nota firmada por Francisco de Lezica y Anselmo Sáenz Valiente. Buenos Aires, 8 de julio de 1806 .

Informe sin fecha de Manuel Martín de la Calleja.

Serie Comandancias $(S C)$, sala IX.

Legajo I-4-2

Carta de Miguel Tejedor a Joaquín del Pino. Cabeza del Buey, 24 de noviembre de 1803 .

Legajo I-4-3

Carta de Manuel Fernández a Nicolás Arredondo. Chascomús, io de noviembre de 1790 .

Nota al comandante del fuerte de Chascomús. Buenos Aires, 24 de junio de I803.

Carta de Juan Andrada al virrey Santiago Liniers. Frontera de Chascomús, 20 de agosto de 1808 .

Legajo I-4-6

Carta de Marcos González Balcarce a Joaquín del Pino. Frontera del Monte, 4 de agosto de 1802 . 
Carta de Juan Barragán a Baltasar Hidalgo y Cisneros. Frontera del Monte, 4 de septiembre de 1809 .

Legajo I-6-6

Carta de Antonio de Olavarría a Joaquín del Pino. Frontera de Luján, i8 de diciembre de 180 .

Legajo I-7-I

Carta de Antonio de Olavarría al marqués de Sobre Monte. Frontera de Luján, 4 de marzo de i8o5.

Carta de Joaquín Antonio de Mosquera [al Capitán general Presidente].

Guardia de Luján, 26 de octubre de i 808 .

\section{B. Impresos}

Acuerdos del extinguido Cabildo de Buenos Aires. 1805-1807. Buenos Aires: Archivo General de la Nación, Kraft, 1926.

\section{FUENTES SECUNDARIAS}

Bechis, Martha. "La contribución de los amerindios a la creación de las nacionalidades argentina y chilena, un enfoque antropológico". Piezas de etnobistoria y de antropología histórica. 1984-1985. Buenos Aires: Sociedad Argentina de Antropología, 2010, pp. 29-45.

Blommaert, Jan. Discourse: A Critical Introduction. Cambridge: Cambridge University Press, 2006.

Chiaramonte, José Carlos. Ciudades, provincias, estados. Origenes de la nación argentina (I800-1846). Buenos Aires: Emecé, 2007.

Connerton, Paul. How Societies Remember. Cambridge: Cambridge University Press, 1989.

Cordero, Héctor A. "En torno a los indios en las invasiones inglesas". La Prensa (Buenos Aires), suplemento cultural, junio de i97r.

Crivelli Montero, Eduardo. "Malones: ¿saqueo o estrategia? El objetivo de las invasiones de 1780 y 1783 a la frontera de Buenos Aires". Todo es Historia, n. ${ }^{\circ} 283$, I991, pp. 6-32.

---. "Pactando con el enemigo: la doble frontera de Buenos Aires con las tribus hostiles en el

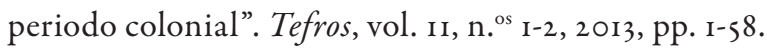

Cuadra Centeno, Pablo Andrés y María Laura Mazzoni. “La invasión inglesa y la participación popular en la reconquista y defensa de Buenos Aires, 1806-1807”. Anuario del Instituto de Historia Argentina, n. ${ }^{\circ}$ I I, 201 I, pp. 43-71, http://www.memoria.fahce. unlp.edu.ar/art_revistas/pr.5243/pr.5243.pdf. 
Davis, Natalie Zemon. "El historiador y los usos literarios". Revista Historia y Justicia, n. ${ }^{\circ}$ I, 2013 , pp. I-7.

Galarza, Antonio y Guillermo Banzato. "Ejercer el poder en un pueblo de frontera: Juan Lorenzo Castro, hacendado, pulpero y alcalde de Chascomús (Buenos Aires) a inicios del siglo XIX”. Prohistoria, n. ${ }^{\circ}$ 21, 2014, pp. 105-129.

Gallo, Klaus. De la invasión al reconocimiento. Gran Bretaña y el Rio de la Plata, I806-I826. Buenos Aires: AZ Editora, 1994.

Guerrero, Andrés. Administración de poblaciones, ventriloquia, y transescritura. Lima: Flacso, sede Ecuador; Instituto de Estudios Peruanos, 20 ro.

Halperín Donghi, Tulio. El ocaso colonial en Hispanoamérica. Buenos Aires: Sudamericana, 1978 .

Hernández, Isabel. Los indios de Argentina. Quito: Abya Yala, I995.

Kerbrat Orecchioni, Catherine. La enunciación. De la subjetividad en el lenguaje. Buenos Aires: Hachette, 1987.

Levaggi, Abelardo. Paz en la frontera. Historia de las relaciones diplomáticas con las comunidades indigenas en la Argentina (siglos XVI-XIX). Buenos Aires: Universidad del Museo Social Argentino, 2000.

Mandrini, Raúl. "Desventuras y venturas de un gallego en el Buenos Aires de fines de la Colonia. Don Blas Pedrosa”. Vivir entre dos mundos, editado por Raúl Mandrini. Buenos Aires: Taurus, 2006, pp. 43-72.

---. “Las fronteras y la sociedad indígena en el ámbito pampeano”. Anuario del IEHS, n. ${ }^{\circ}$ I2, 1997, pp. 23-34.

Martínez Sarasola, Carlos. "El Mayo indígena”. jLibertad, muera el tirano!: el camino a la independencia en América, por Gustavo Baeza et al. Buenos Aires: Ediciones Madres de Plaza de Mayo, 2006, pp. 51-102.

---. Nuestros paisanos los indios. Vida, historia y destino de las comunidades indigenas en la Argentina. Buenos Aires: Emecé, 1992.

Mitre, Bartolomé. Historia de Belgrano y de la Independencia Argentina, tomo i. Buenos Aires: Félix Lajouane Editor, 1887.

Molinari, José Luis. "Los indios y los negros durante las invasiones inglesas al Río de la Plata en 1806 y 1807 ”. Boletín de la Academia Nacional de Historia, n. ${ }^{\circ}$ 34, 1963, pp. 639-673.

Nacuzzi, Lidia R. "Los caciques amigos y los espacios de la frontera sur de Buenos Aires en el siglo XVIII". Tefros, vol. I2, n. ${ }^{\circ}$ 2, 2014 , pp. I03-139. 
---. "Los grupos étnicos y sus territorios en las fronteras del río Salado de Buenos Aires (siglo XVIII)". Población \& Sociedad, vol. 21, n. ${ }^{\circ}$ 2, 2014 , pp. 5-32.

---. Identidades impuestas. Tehuelches, aucas y pampas en el norte de la Patagonia. Buenos Aires: Sociedad Argentina de Antropología, 1998.

Nacuzzi, Lidia y Carina Lucaioli. “'Y sobre las armas se concertaron las paces': explorando las rutinas de los acuerdos diplomáticos coloniales". Revista Cultura, Hombre, Sociedad (Cuhso), vol. I5, n. ${ }^{\circ}$ 2, 2008 , pp. 6I-74.

Nacuzzi, Lidia y Luisina Tourres. “Acuerdos del Cabildo de Buenos Aires”. Entre los datos y los formatos. Indicios para la historia indigena de las fronteras en los archivos coloniales, coordinado por Lidia Nacuzzi. Buenos Aires: CAS; IDES, 2018, pp. 29-68.

Pérez Ruiz, Lucio. "Reacción de los pueblos y ayuda de los aborígenes del Virreinato del Río de la Plata ante las invasiones". Cuadernos de Historia Jerónimo Zurita, n. ${ }^{\circ}$ I6-i8, 1963-1965, pp. 261-274.

Pérez Samper, María de los Ángeles. "La imagen de la monarquía española en el siglo XVIII". Obradoiro de Historia Moderna, n. ${ }^{\circ}$ 20, 2011 , pp. I05-139. DoI: https://doi. org/I0.15304/ohm.20.9.

Puigróss, Rodolfo. De la Colonia a la Revolución. Buenos Aires: Carlos Pérez, 1969.

Quijada, Mónica. "Indígenas: violencia, tierras y ciudadanía”. Homogeneidad y nación con un estudio de caso: Argentina, siglos XIX y XX, editado por Mónica Quijada, Carmen Bernand y Arnd Schneider. Madrid: CSIC, 2000 , pp. 57-92.

Ramos, Ana. "Perspectivas antropológicas sobre la memoria en contextos de diversidad y desigualdad". Alteridades, vol. 21, n. ${ }^{\circ}$ 42, $201 \mathrm{I}$, pp. I3I-I 48.

Ratto, Silvia. “¿Revolución en las pampas? Diplomacia y malones entre los indígenas de Pampa y Patagonia”. ¿Y el pueblo dónde está? Contribuciones para una historia popular de la Revolución de Independencia en el Rio de la Plata, editado por Raúl Fradkin. Buenos Aires: Prometeo, 2015, pp. 207-234.

Roulet, Florencia. "Con la pluma y la palabra. El lado oscuro de las negociaciones de paz entre españoles e indígenas". Revista de Indias, vol. 64, n. ${ }^{\circ}$ 231, 2004, pp. 313-347, https://doi.org/ı0.3989/revindias.2004.i231.543.

---. Huincas en tierra de indios. Mediaciones e identidades en los relatos de viajeros tardocoloniales. Buenos Aires: Eudeba, 2016.

Socolow, Susan. "La burguesía comerciante de Buenos Aires en el siglo Xviı". Desarrollo Económico, vol. 18, n. ${ }^{\circ} 70,1978$, pp. $205-216$.

Tamagnini, Marcela y Graciana Pérez Zavala. "El tratado de paz de 1796: entre la delimitación de la frontera sur cordobesa y el reconocimiento político de los ranqueles". Sociedades de Paisajes Áridos y Semiáridos, vol. I, n. ${ }^{\circ}$ I, 2009, pp. 167-184. 
Taruselli, Gabriel. "Las expediciones a Salinas: caravanas en la pampa colonial. El abaste-

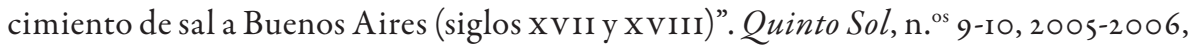
pp. I25-I 49.

Ternavasio, Marcela. Historia de la Argentina, I806-1852. Buenos Aires: Siglo XX, 2009.

Tourres, Luisina. "Los usos sociales del pasado en la construcción nacional-estatal: la representación de la propuesta de una monarquía incaica (1816) en la historiografía de Mitre". Anuario de la Escuela de Historia Virtual, n. ${ }^{\circ}$ I3, 2018, pp. 24-4I.

Trouillot, Michel-Rolph. Silencing the Past. Power and the Production of History. Boston: Beacon Press, 1995.

Zerda, Wellington. Los indios y las invasiones inglesas. Buenos Aires: Claridad, 1934.

\section{$\infty$}

\section{A N E X O}

\section{Discurso atribuido a los caciques en el Cabildo de Buenos Aires y respuesta de los cabildantes,}

\section{2 de diciembre de 1806 (Acuerdos 362-364)}

En este estado se avisó por el Portero que diez caciques de estas Pampas pedían permiso para entrar en la Sala, y habiéndolo obtenido entraron, tomaron asiento y arengaron por medio de intérprete en la forma siguiente: A los hijos del Sol: a los que tan largas noticias tenemos de lo que han ejecutado en mantener estos Reinos; a los que gloriosamente habéis echado a esos colorados de vuestra casa, que lograron tomar por una desgracia; a vosotros que sois los Padres de la Patria, venimos personalmente a manifestaros nuestra gratitud, no obstante que por nuestros diferentes enviados os tenemos ofrecido cuantos auxilios y recursos nos acompañan: Hemos querido conoceros por nuestros ojos, y llevamos el gusto de haberlo conseguido; y pues reunidos en esta grande habitación donde igualmente vemos a nuestros Reyes, en su presencia y no satisfechos de las embajadas que os tenemos hechas, os ofrecemos nuevamente reunidos todos los grandes Caciques que veis, hasta el número de veinte mil de nuestros súbditos, todos gente de guerra y cada cual con cinco caballos; queremos sean los primeros a embestir a esos colorados que parece aun os quieren incomodar. Nada os pedimos por todo esto y más que haremos en vuestro obsequio: todo 
os es debido, pues que nos habéis libertado, que tras de vosotros siguieran en nuestra busca: tendremos mucha vigilancia [para] rechazarlos por nuestras costas donde contamos con mayor número de gente que el que os llevamos ofrecido: nuestro reconocimiento en la buena acogida que dais a nuestros frutos, y permiso libre con que sacamos los que necesitamos es lo bastante a recompensarnos con este pequeño servicio: mandan sin recelo, ocupad la sinceridad de nuestros corazones, y esta será la mayor prueba y consuelo que tendremos: así lo esperamos ejecutaréis, y será perpetuo vuestro nombre en lo más remoto de nuestros súbditos, que a una voz claman por vuestra felicidad, que deseamos sea perpetua en la unión que os juramos.

Concluida la arenga hicieron su cortesía, se pararon todos; procedieron los Señores a abrazar a los diez caciques, que manifestaron mucho contento con ello, y el Señor Alcalde de primer Voto habló en estos términos: El Cabildo ha oído con indecible gozo el afecto y reconocimiento que merece a los grandes Caciques que tiene a la vista. Si hasta hoy han conocido cuánto se ha esmerado en contribuir a su prosperidad en cumplimiento de las disposiciones de sus Soberanos que tanto los ama y recomienda, ahora con mayor razón deben esperar se aumente la protección que les dispensa por la fidelidad con que se ofrecen gustosos a defender sus dominios. Este Cuerpo admite la unión que le juráis, y en prueba de ello os abraza como a fieles hermanos, no dudando ni por un momento cumpliréis con exactitud cuanto le habéis ofrecido siempre que la necesidad exija vuestro servicio, en cuyo caso se os dará aviso por quien corresponda. Por ahora no hay un motivo para que os incomodéis. La fidelidad, amor, y patriotismo de las numerosas y esforzadas tropas que en cuerpos se hallan formadas, aseguran la defensa de esta hermosa Capital, y por lo mismo solo os recomienda hoy el celo y vigilancia de nuestras Costas, para que los Ingleses nuestros enemigos y vuestros a quienes llamáis colorados, no os opriman ni priven vivir con tranquilidad que disfrutáis, y os ha proporcionado el Superior Gobierno, conforme en todo a la sensibilidad y amor que os profesan los mejores y más benignos de los Soberanos del Mundo, de quienes somos vasallos, y a quienes daremos cuenta de vuestra heroica fidelidad. El altísimo os mantenga en iguales sentimientos para que de este modo seáis siempre felices. Acabada esta oración hicieron todos varias demostraciones de agradecimiento, los Señores mandaron se les obsequiase y gratificase, se retiraron los Caciques, y dichos Señores lo firmaron de que doy fe. 